\section{MAXIMISE POTENTIAL}

Ensuring that you maximise income potential is paramount when running your own practice.

Kodak Back-Office is a new software package from PracticeWorks designed specifically for the dental industry. It will help you become more business efficient, eliminating any strain from the critical management areas in your dental practice. Users will benefit from the support of established dental accounting professionals who have teamed up with Kodak to offer support.

Modules include: staff records, suppliers, purchase ledger, stock control, deliveries, petty cash, banking and full nominal accounts and reports. You will have complete control of your practice finances and management information.

www.practiceworks.co.uk

\section{INFECTION CONTROL}

In the Little Sister range, Eschmann has used its expertise to develop practical, easy to use and fully compliant equipment for all your cleaning, disinfection and sterilisation needs.

Customers can purchase products directly from Eschmann, with additional service and warranty provided by Eschmann's own team of 60 fully qualified engineers, included as standard. This method of purchase offers complete peace of mind by ensuring that the equipment consistently reproduces the expected quality of result. There is a solution for every budget, with a choice of one-off payments, interest free payments over ten months or affordable, fixed monthly payments with a LeasePlan to spread the cost over a fixed term.
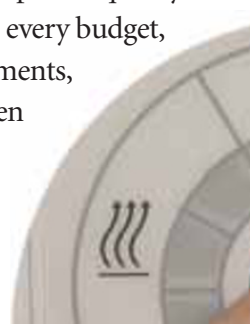
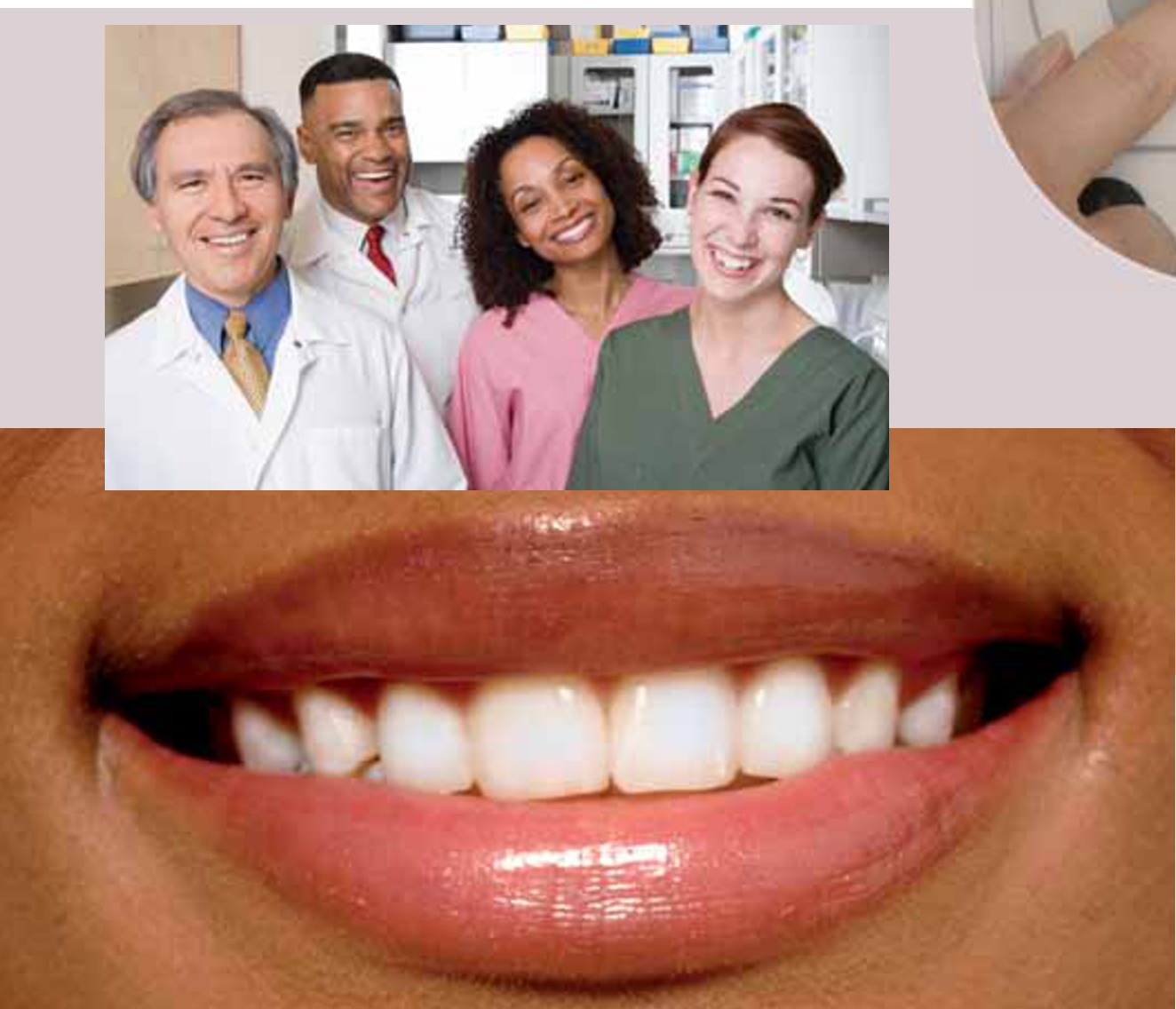

With self-checking cycles and one-touch operation facilitating proper use, the 11 litre autoclave saves water, energy and time, while the other model has a massive 22 litre capacity to maintain instrument flow even in the busiest practice, especially where a recommended washer disinfector is also used.

With a choice of underbench and benchtop models, the Little Sister range of instrument washer disinfectors provides an alternative to the vagaries of manual and ultrasonic cleaning.

All Little Sisters employ colour-coded trays to boost efficiency and organisation, and Hands

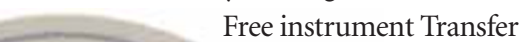
needle stick injuries. Call 01903875787 for more information.

\section{TRAINING FOR WHITENING}

Do you have the necessary skills that the GDC are looking for to whiten your patients' teeth safely and effectively?

James Goolnik has been dealing for years with patients who have had their teeth permanently damaged by tooth whitening. $\mathrm{He}$ believes that now the GDC has relaxed the rules and allowed dental hygienists and therapists to carry out whitening treatments there may be more patients harmed. He believes they will need suitable training to safely carry out these procedures and teach their dentist what 'an adequate prescription' is. So much so that he has set up a company 'Smiles by James Goolnik' to specifically train dental hygienists and therapists in tooth whitening.

Based in central London trainees will spend a full day learning the theory of tooth whitening and then have hands-on practice of both power and home whitening. See www.nowsmile.com for further details and to book.

\section{TWO WEEK TRIAL}

Look across any practice or reception area and you'll see staff slouched on their chair in a position guaranteed to deliver a lifetime of bad backs, sore necks and painful shoulders.

But sitting in comfort while working is easy to achieve with the ergonomically designed DynamoSeat and InCharge stools from Evident. These stools automatically correct your seating position, providing the perfect balance, maximum support and comfort, ensuring you work in comfort all day long.

Evident is so confident you'll benefit from sitting on a DynamoSeat or InCharge stool, they're offering a free two-week in-practice trial, so you can see the benefits yourself.

The DynamoSeat and InCharge stools are available in a variety of styles and colours and are remarkable value for money. For more information telephone 0500321111. 